\title{
Male gender, Charnley class C, and severity of bone defects predict the risk for aseptic loosening in the cup of ABG I hip arthroplasty
}

Jiri Gallo ${ }^{1 *}$, Vitezslav Havranek², Jana Zapletalova ${ }^{3}$, Jiri Lostak ${ }^{1}$

\begin{abstract}
Background: We studied which factor could predict aseptic loosening in ABG I hip prosthesis with hydroxyapatite coating. Aseptic loosening and periprosthetic osteolysis are believed to be caused, at least in part, by increased polyethylene (PE) wear rate via particle disease. Based on it, increased PE wear rate should be associated with aseptic loosening regardless of the type of implant.

Methods: We analyzed data from 155 revisions of ABG I hip prostheses to examine the influence of patient, implant, surgery, and wear related factors on the rate of aseptic loosening at the site of the cup. This was calculated by stepwise logistic regression analysis. The stability of the implant and severity of bone defects were evaluated intraoperatively.
\end{abstract}

Results: We found that men (odds ratio, $\mathrm{OR}=5.6 ; p=0.004$ ), patients with Charnley class $C(\mathrm{OR}=6.71 ; p=0.013)$, those having more severe acetabular bone defects ( $O R=4$ for each degree of severity; $p=0.002)$, and longer time to revision surgery $(O R=1.51$ for each additional year; $p=0.012$ ) had a greater chance of aseptic loosening of the cup. However, aseptic loosening was not directly predicted by polyethylene wear rate in our patients.

Conclusion: Severity of bone defects predicts the risk for aseptic loosening in ABG I cup. Factors potentially associated with the quality of bone bed and biomechanics of the hip might influence on the risk of aseptic loosening in this implant.

\section{Background}

Aseptic loosening is the most frequent cause of total hip arthroplasty (THA) failure [1]. Both mechanical and biological mechanisms are potentially involved. Mechanical factors include the initially compromised fixation interface of the implant; biological factors are associated with the particle disease that expands over the initial firmly developed bone-prosthesis interface [2]. Accordingly, wear debris derived from an artificial joint triggers multiple adverse host reactions involving signaling pathways which eventually result in osteoclast-mediated bone resorption [3-5]. Based on this, periprosthetic osteolysis undermines aseptic loosening and, therefore, a higher

\footnotetext{
* Correspondence: jiri.gallo@volny.cz

'Department of Orthopaedics, Palacky University Faculty of Medicine and Dentistry \& Teaching Hospital, I. P. Pavlova 6, 77520 Olomouc, Czech Republic

Full list of author information is available at the end of the article
}

wear rate carries a correspondingly higher risk for failure due to aseptic loosening [6].

The term "aseptic loosening" is tightly related to a finding of gross mechanical instability at the interface between implant and bone bed. The multiple factors that influence aseptic loosening can be divided into those related to the patient, the implant, or the surgery. Known influences on aseptic loosening include variables related to polyethylene wear rate, size of periprosthetic osteolysis, design-related variables (i.e. prosthetic material and shape, fixation surface, etc.), surgical experience and technique (quality of implant settlements), and primary diagnosis [7-9]. Other factors that may be important, but are not readily analyzed, include interactions between the implant and its surroundings such as composition of joint fluid, type of lubrication, individual motion/stress pattern, and genetic predisposition [10].

In our previous studies, we found that a high risk for an increased wear rate was associated with ABG I 
prosthesis [11]. We also found a significant association between wear rate and severity of osteolysis in ABG I prosthesis, and an unacceptably high rate of aseptic loosening in ABG I cups $[12,13]$. As with the latter finding, we were interested as to whether there are significant predictors of aseptic loosening in ABG I THA. The identification of such predictors may be useful in understanding the factors associated with aseptic loosening, with the goal being to prevent loosening and reduce the need for surgical revision.

\section{Methods}

\section{Patients}

Patients undergoing surgical revision of ABG I prosthesis between August 2000 and December 2005 were included in this study. The revised cases belonged to a group of patients who had previously undergone the operation at the author's institution between September 1994 and January $2000(\mathrm{n}=506)$. We previously reported on the risk for high wear rate and severe bone defects in these patients [12]. The ethical committee of the institution approved the study protocol and all revisions were performed under standard conditions with the written informed consent of all study patients. A single surgeon performed the majority of revisions (>90\%).

\section{Prosthesis}

The first generation of modular, cementless hip prosthesis with hydroxyapatite coating (HAC) was used (ABG I, Howmedica, Inc., Staines, England). We described the details concerning this implant, HAC, and surgery previously [13].

\section{Wear measurement}

The wear measurements of retrieved polyethylene liners were performed by one of the authors $(\mathrm{VH})$. The measurement technique and basic characteristics are described elsewhere [11].

\section{Clinical and radiographic evaluation}

All of the patient's hips included in the study had stable prosthesis one year after the index surgery based on a review of radiology reports. All study participants were clinically and radiographically examined prior to revision surgery using the same protocol. Anteroposterior pelvic $\mathrm{X}$-rays were performed with the patient in a supine (non-weight-bearing) position. The cup position relative to the true acetabular region was determined [14], as well as the cup position in regard to the lateral part of the tear drop figure and the abduction angle of the cup. The position of the cup relative to the floor of acetabulum was graded as lateral, in contact, or medial depending on the relationship between the most medial part of the cup and Kohler's line. The abduction angle is the angle formed by a horizontal line along the teardrop, ischial tuberosities, or obturator foramina and a line along the open face of the cup. Aseptic loosening was detected intraoperatively in cases where implant instability was revealed after a weak levering of special tools for the cup/stem removal. Intraoperatively, bone defects were evaluated and distinguished at the acetabular site as no significant bone loss (type I), contained bone loss (type II), moderate uncontained bone loss (type III), severe uncontained bone loss (types IV), and pelvic discontinuity (type V) [15]. The same classification was used to evaluate bone defects in the femur.

The Charnley classification was applied to estimate the level of walking capacity, with class A indicating no disturbance in locomotion, class B indicating bilateral hip disease and normal findings in other weight-bearing joints, and class $\mathrm{C}$ representing severe compromise of locomotion due to multiple joint involvement [16].

\section{Statistics}

The primary goal of the study was to identify predictors of aseptic loosening. At first, all data were analyzed using univariate analysis. The categorical variables were compared with use of Fisher's exact test. The results of continuous variables were compared with use of MannWhitney U test or Student's t-test depending on the result of the Shapiro-Wilk test. The accepted significance level was 0.05 . Then, we chose stepwise logistic regression analysis because of the stable and unstable status of the cup. Predictors for aseptic loosening in retrieved ABG I cups were simultaneously analyzed relative to variables contained in Tables 1 and 2. A stepwise variable entry continued if the inclusion $\alpha$ value was less than or equal to 0.05 . Variables with no significant association to the aseptic loosening of the cup were removed from the model. This sequential inclusion/ exclusion of independent variables according to stepwise criteria led eventually to the selection of an independent variable that significantly influence on the variability of the dependent variable [17]. The results were interpreted as an estimate of the change in risk per unit increase of each continuous variable or difference in risk to a reference level in case of categorical variables. Statistical analysis was performed with the commercial SPSS 15.0 package (SPSS Inc., Chicago, IL, USA).

\section{Results}

The study included 155 patients (44 men, 111 women) who had surgical revisions of THA after a mean of 6 years from the index surgery $(5.96 \pm 0.15$ years; mean \pm standard deviation, SD). The reasons for revision were periprosthetic osteolysis $(\mathrm{n}=115 ; 74 \%)$, aseptic loosening of the cup $(\mathrm{n}=32 ; 21 \%)$ or stem $(\mathrm{n}=2 ; 1 \%)$, and 
Table 1 Categorical variables included in the study

\begin{tabular}{|c|c|c|c|c|c|}
\hline & & $\begin{array}{r}\text { Stable implant } \\
(\mathrm{N}=121)\end{array}$ & $\begin{array}{r}\text { Unstable cup } \\
(\mathrm{N}=32)\end{array}$ & & $\begin{array}{r}\text { Unstable stem } \\
(\mathrm{N}=2)\end{array}$ \\
\hline Variable & Categories & N. of hips (\%) & N. of hips (\%) & $P^{a}$ & N. of hips (\%) \\
\hline \multirow[t]{4}{*}{ Gender } & Men & $33(27)$ & $11(34)$ & 0.511 & $0(0 \%)$ \\
\hline & Women & $88(73)$ & $21(66)$ & & $2(100 \%)$ \\
\hline & Osteoarthritis & $27(22)$ & $2(6)$ & & $0(0)$ \\
\hline & Hip dysplasia & $56(46)$ & $14(44)$ & & $1(50)$ \\
\hline \multirow[t]{5}{*}{ Primary diagnosis } & Osteonecrosis & $20(17)$ & $10(31)$ & 0.078 & $0(0)$ \\
\hline & Traumatic & $9(7)$ & $5(16)$ & & $0(0)$ \\
\hline & Inflammatory & $4(3)$ & $1(3)$ & & $1(50)$ \\
\hline & Others & $5(4)$ & $0(0)$ & & $0(0)$ \\
\hline & A & $42(35)$ & $11(34)$ & & $0(0)$ \\
\hline \multirow[t]{2}{*}{ Charnley type } & B & $73(60)$ & $14(44)$ & 0.012 & $2(100)$ \\
\hline & C & $6(5)$ & $7(22)$ & & $0(0)$ \\
\hline \multirow[t]{2}{*}{ Liner geometry } & Neutral & $96(79)$ & $27(84)$ & & $2(100)$ \\
\hline & Hooded & $25(21)$ & $5(16)$ & 0.623 & $0(0)$ \\
\hline \multirow[t]{2}{*}{ Head material } & $\mathrm{CoCr}$ & $111(92)$ & $31(97)$ & & $1(50)$ \\
\hline & Zirconia & $10(8)$ & $1(3)$ & 0.460 & $1(50)$ \\
\hline \multirow[t]{3}{*}{ Cup relation to $\mathrm{KL}$} & Laterally & $10(8)$ & $4(12.5)$ & & $0(0)$ \\
\hline & In contact & $23(19)$ & $4(12.5)$ & 0.565 & $0(0)$ \\
\hline & Medially & $88(73)$ & $24(75)$ & & $2(100)$ \\
\hline \multirow[t]{3}{*}{ True acetabular region } & Yes & $97(80)$ & $26(81)$ & & $0(0)$ \\
\hline & No & $24(20)$ & $6(19)$ & 1.000 & $2(100)$ \\
\hline & Type I, II & $41(34)$ & $2(6)$ & & $1(50)$ \\
\hline \multirow[t]{3}{*}{ Acetabular BD } & Type III & $67(55)$ & $19(60)$ & 0.0003 & $1(50)$ \\
\hline & Type IV, V & $13(11)$ & $11(34)$ & & $0(0)$ \\
\hline & Type I, II & $99(82)$ & $27(84)$ & & $1(50)$ \\
\hline \multirow[t]{3}{*}{ Femoral BD } & Type III & $19(16)$ & $5(16)$ & 1.000 & $1(50)$ \\
\hline & Type IV & $3(2)$ & $0(0)$ & & $0(0)$ \\
\hline & Implant removal & $1(1)$ & $1(3)$ & & $0(0)$ \\
\hline \multirow[t]{2}{*}{ Type of surgery } & Cup revision & $36(30)$ & $8(25)$ & 0.489 & $0(0)$ \\
\hline & THA revision & $84(69)$ & $23(72)$ & & $2(100)$ \\
\hline
\end{tabular}

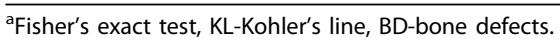

periprosthetic fracture of the femur around stable stem $(\mathrm{n}=6 ; 4 \%)$. Therefore, 34 implants $(22 \%)$ were unstable at the time of revision surgery. Mean polyethylene linear and volumetric wear rates were $0.415 \mathrm{~mm} / \mathrm{y}(0-$ 2.284; SD 0.364) and $153 \mathrm{~mm}^{3} / \mathrm{y}(0-815$; SD 134.4), respectively.

\section{Univariate analysis}

Patients with stable total hip arthroplasty at the time of revision surgery and those with mechanically unstable cup differed significantly in terms of Charnley type ( $p=$ $0.012)$, severity of acetabular bone defects $(p=0.0003)$, and time to revision surgery $(p=0.002)$. Differences in other variables were insignificant (Tables 1 and 2).

In addition, we found a significantly higher polyethylene wear rate in type III femoral bone loss in comparison to bone defects of type I and II (Mann-Whitney U test; $p=0.007$ and $p=0.015$ for linear and volumetric wear rate, respectively).

\section{Stepwise logistic regression}

Among the variables (Tables 1 and 2) that were included in the logistic regression, five significantly predicted an aseptic loosening rate in the ABG I cup (Table 3). The most surprising finding was a potential role for Charnley $\mathrm{C}$ patient type, assuming that these patients have the lowest physical load on the hip. On the other hand, no role was detected for polyethylene wear rate. Logistic regression can determine the percent of variance in the dependent variable explained by the independents to assess the relative importance of independents. Here, the percentage of the variance in the dependent variable explained by the independent variables was above $37 \%\left(R^{2}=0.375\right)$ and the $-2 \log$ 
Table 2 Continuous variables included in the study

\begin{tabular}{|c|c|c|c|}
\hline Variable & Stable implant $(\mathrm{N}=121)$ & Unstable cup ( $\mathrm{N}=32$ ) & $P$ \\
\hline \multirow[t]{2}{*}{ Age at surgery (yrs.) } & $45.6 \pm 7.1$ & $47.8 \pm 5.8$ & $0.102^{\mathrm{a}}$ \\
\hline & $45.4(25.1-64.5)$ & $48.3(37.6-56.7)$ & \\
\hline \multirow[t]{2}{*}{ Height $(\mathrm{cm})$} & $165.7 \pm 8.7$ & $165.4 \pm 9.5$ & $0.864^{\mathrm{a}}$ \\
\hline & $165(150-195)$ & $165(149-187)$ & \\
\hline \multirow[t]{2}{*}{$\overline{\text { Weight (kg) }}$} & $75.1 \pm 14.3$ & $75.2 \pm 14.8$ & $0.918^{b}$ \\
\hline & $73(42-114)$ & $73(50-105)$ & \\
\hline \multirow[t]{2}{*}{ Cup size $(\mathrm{mm})$} & $50.2 \pm 3.7$ & $50.5 \pm 4.1$ & $0.830^{\mathrm{b}}$ \\
\hline & $50(46-60)$ & $49(46-60)$ & \\
\hline \multirow[t]{2}{*}{ PE liner thickness (mm) } & $7.0 \pm 1.9$ & $7.2 \pm 2.0$ & $0.805^{b}$ \\
\hline & $6.9(2.8-11.9)$ & $6.4(4.9-11.9)$ & \\
\hline \multirow[t]{2}{*}{ Abduction angle of the cup $\left(^{\circ}\right)$} & $46.0 \pm 8.2$ & $43.0 \pm 6.3$ & $0.073^{\mathrm{b}}$ \\
\hline & $46(28-72)$ & $43(28-54)$ & \\
\hline \multirow[t]{2}{*}{ Time to revision surgery (yrs.) } & $5.7 \pm 1.8$ & $6.9 \pm 1.8$ & $0.002^{\mathrm{a}}$ \\
\hline & $5.7(2.0-10.4)$ & $6.9(3.7-10.5)$ & \\
\hline \multirow[t]{2}{*}{ Linear wear rate (mm/yrs.) } & $0.42 \pm 0.38$ & $0.39 \pm 0.32$ & $0.764^{b}$ \\
\hline & $0.35(0.0-2.28)$ & $0.31(0.0-1.32)$ & \\
\hline \multirow[t]{2}{*}{ Volumetric wear rate $\left(\mathrm{mm}^{3} / \mathrm{yrs}.\right)$} & $157 \pm 139$ & $144 \pm 119$ & $0.774^{b}$ \\
\hline & $127(0-815)$ & $107(12-467)$ & \\
\hline
\end{tabular}

Mean \pm SD (standard deviation), Median (Range), ${ }^{\text {a }}$ Student's t-test, ${ }^{b}$ Mann-Whitney U-test, PE-polyethylene.

likelihood achieved was beneath 100 indicating a moderate fit of the regression model to the aseptic loosening data.

The vast majority of our patients (109 of $155 ; 70 \%)$ were treated by complete revision of both acetabular and femoral components despite the fact that only two of them experienced loosened stem. The decision to remove stable stem was primarily dependent on surgeon's pre-/intraoperative estimation of its risk for premature failure. In this line, we found that only linear polyethylene wear rate predicts the risk for complete revision $(\mathrm{OR}=36.94$ per each $\mathrm{mm} /$ year; $95 \%$ CI 4.69 290.66; $\left.\mathrm{R}^{2}=0.252\right)$.

\section{Discussion}

According to our analysis, risk for aseptic loosening of the ABG I cup was significantly higher in men, Charnley type $\mathrm{C}$ patients, and those having more severe acetabular bone defects and longer time to surgery. Conversely, a decreased risk for aseptic loosening of the cup was found in patients with higher abduction angle of the cup. On the other hand, the study failed to reveal a direct association between the high polyethylene wear rate and the risk for mechanical loosening of the cup found in an identical type of cementless hip prosthesis.

Aseptic loosening of total hip arthroplasty seems to be a result of a harmful combination of mechanical and biological events destroying the bond between implant and bone bed [2]. Biological mechanisms are tightly associated with increased generation of polyethylene particles, as demonstrated in previous studies [18-20]. Particles can trigger a complex biological reaction involving the development of a chronic inflammatory microenvironment, increased number/activity of osteoclasts at the bone-implant interface, and accumulation of fluid inside the artificial joint $[5,21,22]$. Hypothetically, these mechanisms would together or independently lead to development of bone defects eventually resulting in

Table 3 Variables associated with the probability of aseptic loosening of the cup in ABG I prosthesis

\begin{tabular}{|c|c|c|c|c|c|}
\hline \multirow[t]{2}{*}{ Variable } & \multirow[t]{2}{*}{ Odds ratio } & \multicolumn{2}{|c|}{ 95\% confidence interval } & \multirow[t]{2}{*}{$p$ value } & \multirow[t]{2}{*}{$\mathbf{R}^{2}$} \\
\hline & & Lower bound & Upper bound & & \\
\hline Men & 5.6 & 1.729 & 18.125 & 0.004 & 0.375 \\
\hline Charnley $\mathrm{C}$ type of patient & 6.71 & 1.498 & 30.047 & 0.013 & \\
\hline Increasing acetabular BD by 1 step of severity & 4.06 & 1.647 & 9.980 & 0.002 & \\
\hline Increasing FU by 1 year & 1.51 & 1.096 & 2.086 & 0.012 & \\
\hline Increasing abduction angle of the cup by $1^{\circ}$ & 0.91 & 0.846 & 0.987 & 0.022 & \\
\hline
\end{tabular}

BD-bone defects; FU-follow-up; $\mathrm{R}^{2}$-Nagelkerke R Square. 
aseptic loosening of the implant undermined by bone defects. Because the above-mentioned pathways depend on a continuous delivery of huge amounts of particles [6] a relationship between aseptic loosening and polyethylene wear rate is expected. In fact, we failed to demonstrate a direct association between high polyethylene wear rate and aseptic loosening of the ABG I cup. On the other hand, we revealed a strong predictive power of severity of acetabular bone defects (i.e. size of osteolysis) for aseptic loosening of the ABG I cup. These findings may suggest that periprosthetic osteolysis is an essential pre-requisite for aseptic loosening that, however, requires terminal impulse such as mechanical stress/strain inducing movement of the implant.

It has been previously determined that there is an increased risk of aseptic loosening in men comparing to woman [7,23-25]. Numerous factors might be responsible for this difference, including a higher mechanical stresses at the hip, influencing both the bone-implant interface stability and polyethylene wear rate. In this line some authors analyze the success of total hip arthroplasty in terms of biomechanically favorable hip joint conditions [26]. There may be a role for differences in hip kinematics between men and women in the explanation of gender effects [27]. Recently, Flugsrud et al. observed the existence of increased risk of early revision due to a loose cup in younger men, with a high level of physical activity during leisure time [28]. Unfortunately, there were no data available to allow us to investigate deeply this association.

A question remains as to what other factors could be behind the destabilization of the implant together with the severity of bone defects. Of these, increasing length of follow-up was found to influence the probability of aseptic loosening. Time from index surgery should be related especially to the accumulation of fatigue changes that, in conjunction with increasing size of bone defects, compromise the prosthetic-bone interface leading to degradation of fixation interface with loosening of the implant. Additionally, there is ongoing concern regarding the integrity of HAC, such as the potential for debonding of hydroxyapatite layers from a substrate or dissolution of HAC, both possibly resulting in the loss of bone-implant interface and aseptic loosening [20,29]. In our experience, ABG I cup did not work well during follow-up periods even less than 10 years, with an overall 12-year cumulative survival of 0.55 (95\% CI, 0.443-0.659) [13]. Several other studies including registry-based ones has confirmed our experiences with ABG I [30-33]. Catastrophic wear in THA could be prevented at least partially by utilizing alternative bearing surfaces such ceramic on ceramic, especially in younger patients.

It is not clear why patients of Charnley type $C$ could be predisposed to aseptic loosening of the cup. Their hips should have the least exposure to repetitive and robust mechanical load in comparison to other Charnley types. However, this could be the reason as poor bone bed quality could result from the lowest periimplant bone stresses [34]. Bone homeostasis requires regular mechanical stimuli of an adequate level and time, in accordance to Wolff's law [35]. It may be assumed that patients with multilevel damage of the locomotory apparatus demonstrate lower mechanical stimuli to the bone than patients of Charnley class A or B. However, doubt has emerged recently concerning the validity of Charnley classification for evaluation of true physical level [36]. Moreover, a discrepancy has been found between patient data on physical activity obtained before surgery and his/her true activity after the surgery [37-39]. Finally, the relationship between periprosthetic bone turnover and the level of physical activity is not linear but exhibits myriad of multilevel interactions involving biological, mechanical, and prosthetic factors.

Our study and others found an association between increased abduction angle and risk of higher polyethylene wear rate, which then increases the severity of periprosthetic osteolysis $[8,12,40]$. In this line, it might be surprising that we found the risk for aseptic loosening of the ABG I cup to diminish with increasing abduction angle of the cup. It can be expected that an inappropriate cup position together with high load conditions could induce micromovements, overcoming the strength of the boneimplant interface weakened by periprosthetic osteolysis [41]. On the other hand, it should be stressed that in our study the difference in abduction angle between stable and unstable cups was not significant on univariate analysis.

The main weakness of our study is that only revised THAs were included in the analysis while those that were not revised did not affect the outcome of the study. This concern might be theoretically diminished by an adequate number of cases with stable THA in contrast to those with unstable cups.

\section{Conclusion}

In summary, this study reported an unacceptably high rate of aseptic loosening of the cup in ABG I THA related predominantly to severe periprosthetic osteolysis. We did not identify a significant association between aseptic loosening and polyethylene wear, which suggests the involvement of other factors, in particular mechanical, to terminate aseptic loosening in periprosthetic osteolysis. Our data should be also interpreted in relation to the choice of bearing surface which is vital for the success of THA especially in younger patients.

\section{List of abbreviations}

ABG I: the Anatomique Benoist Girard hip prosthesis of 1st generation; Cl: confidence interval; HAC: hydroxyapatite coating; OR: odds ratio; SD: standard deviation; THA: total hip arthroplasty. 


\section{Acknowledgements}

The study was supported by the Ministry of Education, Youth and Sports of the Czech Republic grant MSM6198959223 and was presented at the 11 EFORT Congress, 2-5 June 2010, Madrid, Spain.

\section{Author details}

'Department of Orthopaedics, Palacky University Faculty of Medicine and Dentistry \& Teaching Hospital, I. P. Pavlova 6, 77520 Olomouc, Czech Republic. ${ }^{2}$ Joint Laboratory of Optics, Palacky University, Institute of Physics, Academy of Sciences of Czech Republic, Tr. 17. listopadu 50, 77207 Olomouc, Czech Republic. ${ }^{3}$ Department of Biophysics, Faculty of Medicine and Dentistry, Palacky University, Hnevotinska 3, 77515 Olomouc, Czech Republic.

\section{Authors' contributions}

JG organized the study, recruited THA patients into the study and collected clinical/radiographic details. VH carried out polyethylene wear measurement. JZ performed the statistical analysis. JL contributed to the discussion of the results. The manuscript was primarily written by JG but all authors read and approved the final version of manuscript.

\section{Authors' information}

Associated Professor Jiri Gallo, MD, PhD is the chief of Department of Orthopaedics, Teaching Hospital, Faculty of Medicine and Dentistry, Palacky University, Czech Republic.

Vitezslav Havranek, MS is the researcher at the Joint Laboratory of Optics, Palacky University, Institute of Physics, Academy of Sciences of Czech Republic.

Jana Zapletalova, MS, PhD is the senior statistician at the Department of Biophysics, Faculty of Medicine, Palacky University, Czech Republic. Jiri Lostak, MD is the clinical fellowship in orthopaedics affiliated at the Department of Orthopaedics, Teaching Hospital, Faculty of Medicine and Dentistry, Palacky University, Czech Republic.

\section{Competing interests}

The authors declare that they have no competing interests.

Received: 12 June 2010 Accepted: 19 October 2010

Published: 19 October 2010

\section{References}

1. Ulrich SD, Seyler TM, Bennett D, Delanois RE, Saleh KJ, Thongtrangan I, Kuskowski M, Cheng EY, Sharkey PF, Parvizi J, et al: Total hip arthroplasties: What are the reasons for revision? Int Orthop 2008, 32(5):597-604.

2. Sundfeldt M, Carlsson LV, Johansson CB, Thomsen P, Gretzer C: Aseptic loosening, not only a question of wear: a review of different theories. Acta Orthop 2006, 77(2):177-197.

3. Goodman SB: Wear particles, periprosthetic osteolysis and the immune system. Biomaterials 2007, 28(34):5044-5048.

4. Abu-Amer Y, Darwech I, Clohisy JC: Aseptic loosening of total joint replacements: mechanisms underlying osteolysis and potential therapies. Arthritis Res Ther 2007, 9(Suppl 1):S6.

5. Konttinen YT, Zhao D, Beklen A, Ma G, Takagi M, Kivela-Rajamaki M, Ashammakhi N, Santavirta S: The microenvironment around total hip replacement prostheses. Clin Orthop Relat Res 2005, 430: 28-38.

6. Wilkinson JM, Hamer AJ, Stockley I, Eastell R: Polyethylene wear rate and osteolysis: critical threshold versus continuous dose-response relationship. J Orthop Res 2005, 23(3):520-525.

7. Bordini B, Stea S, De Clerico M, Strazzari S, Sasdelli A, Toni A: Factors affecting aseptic loosening of $\mathbf{4 7 5 0}$ total hip arthroplasties: multivariate survival analysis. BMC Musculoskelet Disord 2007, 8:69.

8. Little NJ, Busch CA, Gallagher JA, Rorabeck CH, Bourne RB: Acetabular polyethylene wear and acetabular inclination and femoral offset. Clin Orthop Relat Res 2009, 467(11):2895-2900.

9. Roder C, Eggli S, Munger P, Melloh M, Busato A: Patient characteristics differently affect early cup and stem loosening in THA: a case-control study on 7,535 patients. Int Orthop 2008, 32(1):33-38.

10. Tuan RS, Lee FY, Y TK, Wilkinson JM, Smith RL: What are the local and systemic biologic reactions and mediators to wear debris, and what host factors determine or modulate the biologic response to wear particles? J Am Acad Orthop Surg 2008, 16(Suppl 1):S42-48.

11. Gallo J, Havranek V, Cechova I, Zapletalova J: Wear measurement of retrieved polyethylene ABG 1 cups by universal-type measuring microscope and X-ray methods. Biomed Pap Med Fac Univ Palacky Olomouc Czech Repub 2006, 150(2):321-326.

12. Gallo J, Havranek V, Zapletalova J: Risk factors for accelerated polyethylene wear and osteolysis in ABG I total hip arthroplasty. Int Orthop 2010, 34(1):19-26.

13. Gallo J, Langova K, Havranek V, Cechova I: Poor survival of ABG I hip prosthesis in younger patients. Biomed Pap Med Fac Univ Palacky Olomouc Czech Repub 2008, 152(1):163-168.

14. Pagnano W, Hanssen AD, Lewallen DG, Shaughnessy WJ: The effect of superior placement of the acetabular component on the rate of loosening after total hip arthroplasty. J Bone Joint Surg Am 1996, 78(7):1004-1014.

15. Saleh KJ, Holtzman J, Gafni A, Saleh L, Davis A, Resig S, Gross AE: Reliability and intraoperative validity of preoperative assessment of standardized plain radiographs in predicting bone loss at revision hip surgery. $J$ Bone Joint Surg Am 2001, 83-A(7):1040-1046.

16. Charnley J: The long-term results of low-friction arthroplasty of the hip performed as a primary intervention. J Bone Joint Surg Br 1972, 54(1):61-76.

17. Wang D, Zhang W, Bakhai A: Comparison of Bayesian model averaging and stepwise methods for model selection in logistic regression. Stat Med 2004, 23(22):3451-3467.

18. Clauss $M$, Luem M, Ochsner PE, Ilchmann T: Fixation and loosening of the cemented Muller straight stem: a long-term clinical and radiological review. J Bone Joint Surg Br 2009, 91(9):1158-1163.

19. Chuter GS, Cloke DJ, Mahomed A, Partington PF, Green SM: Wear analysis of failed acetabular polyethylene: a comparison of analytical methods. J Bone Joint Surg Br 2007, 89(2):273-279.

20. Stilling $M$, Rahbek $O$, Soballe $K$ : Inferior survival of hydroxyapatite versus titanium-coated cups at 15 years. Clin Orthop Relat Res 2009, 467(11):2872-2879

21. Hallab NJ, Jacobs JJ: Biologic effects of implant debris. Bull NYU Hosp Jt Dis 2009, 67(2):182-188.

22. Aspenberg $\mathrm{P}$, Van der Vis $\mathrm{H}$ : Migration, particles, and fluid pressure. A discussion of causes of prosthetic loosening. Clin Orthop Relat Res 1998, 352: $75-80$.

23. Santaguida PL, Hawker GA, Hudak PL, Glazier R, Mahomed NN, Kreder HJ, Coyte PC, Wright JG: Patient characteristics affecting the prognosis of total hip and knee joint arthroplasty: a systematic review. Can J Surg 2008, 51(6):428-436.

24. Munger $P$, Roder $C$, Ackermann-Liebrich $U$, Busato $A$. Patient-related risk factors leading to aseptic stem loosening in total hip arthroplasty: a case-control study of 5,035 patients. Acta Orthop 2006, 77(4):567-574.

25. von Schewelov T, Sanzen L, Onsten I, Carlsson A: Catastrophic failure of an uncemented acetabular component due to high wear and osteolysis: an analysis of 154 omnifit prostheses with mean 6-year follow-up. Acta Orthop Scand 2004, 75(3):283-294

26. The B, Hosman A, Kootstra J, Kralj-lglic V, Flivik G, Verdonschot N, Diercks R: Association between contact hip stress and RSA-measured wear rates in total hip arthroplasties of 31 patients. J Biomech 2008, 41(1):100-105.

27. Chumanov ES, Wall-Scheffler C, Heiderscheit BC: Gender differences in walking and running on level and inclined surfaces. Clin Biomech (Bristol, Avon) 2008, 23(10):1260-1268

28. Flugsrud GB, Nordsletten L, Espehaug B, Havelin LI, Meyer HE: The effect of middle-age body weight and physical activity on the risk of early revision hip arthroplasty: a cohort study of 1,535 individuals. Acta Orthop 2007, 78(1):99-107.

29. Lazarinis S, Karrholm J, Hailer NP: Increased risk of revision of acetabular cups coated with hydroxyapatite. Acta Orthop 2010, 81(1):53-59.

30. Blacha J: High osteolysis and revision rate with the hydroxyapatitecoated ABG hip prostheses: 65 hips in 56 young patients followed for 5 9 years. Acta Orthop Scand 2004, 75(3):276-282.

31. Chung YY, Ki SC, So KY, Kim DH, Park KH, Lee YS: High revision rate of hydroxyapatite-coated ABG-I prosthesis. J Orthop Sci 2009, 14(5):543-547 
32. Delank KS, Drees P, Menzel N, Hansen T, Duschner H, Eckardt A: Increased polyethylene wear after cementless ABG I total hip arthroplasty. Arch Orthop Trauma Surg 2006, 126(8):509-516.

33. Makela KT, Eskelinen A, Paavolainen P, Pulkkinen P, Remes V: Cementless total hip arthroplasty for primary osteoarthritis in patients aged 55 years and older. Acta Orthop 2010, 81(1):42-52.

34. Lengsfeld M, Gunther D, Pressel T, Leppek R, Schmitt J, Griss P: Validation data for periprosthetic bone remodelling theories. J Biomech 2002, 35(12):1553-1564.

35. Frost HM: Vital biomechanics: proposed general concepts for skeletal adaptations to mechanical usage. Calcif Tissue Int 1988, 42(3):145-156.

36. Roder C, Staub LP, Eichler P, Widmer M, Dietrich D, Eggli S, Muller U: Avoiding misclassification bias with the traditional Charnley classification: rationale for a fourth Charnley class BB. J Orthop Res 2006 24(9):1803-1808.

37. Weller IMR, Kunz M: Physical activity and pain following total hip arthroplasty. Physiotherapy 2007, 93:23-29.

38. Wagenmakers R, van den Akker-Scheek I, Groothoff JW, Zijlstra W, Bulstra SK, Kootstra JW, Wendel-Vos GC, van Raaij JJ, Stevens M: Reliability and validity of the short questionnaire to assess health-enhancing physical activity (SQUASH) in patients after total hip arthroplasty. BMC Musculoskelet Disord 2008, 9:141.

39. Morlock M, Schneider E, Bluhm A, Vollmer M, Bergmann G, Muller V, Honl M: Duration and frequency of every day activities in total hip patients. J Biomech 2001, 34(7):873-881.

40. Patil S, Bergula A, Chen PC, Colwell CW Jr, D'Lima DD: Polyethylene wear and acetabular component orientation. J Bone Joint Surg Am 2003, 85A(Suppl 4):56-63.

41. Korhonen RK, Koistinen A, Konttinen YT, Santavirta SS, Lappalainen R: The effect of geometry and abduction angle on the stresses in cemented UHMWPE acetabular cups-finite element simulations and experimental tests. Biomed Eng Online 2005, 4(1):32.

\section{Pre-publication history}

The pre-publication history for this paper can be accessed here: http://www.biomedcentral.com/1471-2474/11/243/prepub

doi:10.1186/1471-2474-11-243

Cite this article as: Gallo et al:: Male gender, Charnley class C, and severity of bone defects predict the risk for aseptic loosening in the cup of ABG I hip arthroplasty. BMC Musculoskeletal Disorders 2010 11:243.

\section{Submit your next manuscript to BioMed Central and take full advantage of:}

- Convenient online submission

- Thorough peer review

- No space constraints or color figure charges

- Immediate publication on acceptance

- Inclusion in PubMed, CAS, Scopus and Google Scholar

- Research which is freely available for redistribution 